\title{
Ambulantes e prontos para a rua: algumas considerações sobre o crescimento das (neo) fanfarras no Rio de Janeiro
}

\section{Ambulant and ready for the road: some considerations on the growth of (neo) Brass Bands in Rio de Janeiro}

Micael Herschmann

Pesquisador CNPq, professor do Programa de Pós-Graduação em Comunicação da UFRJ, onde também dirige o Núcleo de Estudos e Projetos em Comunicação. Atua também como coordenador do GP de Comunicação, Música e Entretenimento da INTERCOM.

Resumo: Tomando como base a pesquisa empírica realizada entre 2012 e 2013 (construída não só a partir da coleta, seleção e análise de matérias veiculadas na mídia impressa tradicional e material postado nas redes sociais, mas também de observaçóes de campo e entrevistas semiestruturadas realizadas com os atores sociais), buscase avaliar em que medida o crescimento do ativismo nômade musical das fanfarras nos espaços públicos vem afetando o cotidiano da cidade do Rio de Janeiro. A hipótese que norteia os argumentos aqui desenvolvidos é a de que há um consistente movimento musical de rua local (concentrado especialmente no Centro) - que envolve não só redes de músicos, mas também produtores e fấs - que vem contribuindo de forma significativa para a construção de territorialidades e imaginários da e/ou na cidade, em suma, vem subsidiando expressivos processos de ressignificação da experiência social nesta urbe.

Palavras-chave: Comunicação, Cultura Urbana, Fanfarras.

Abstract: Based on empirical research conducted between 2012 and 2013 (realized not only from the collection, selection and analysis of articles published in traditional print media and material posted on social networks, but also field observations and semi-structured interviews with actors social), we seek to assess to what extent the growth of musical fanfares nomadic activism in public areas has affected the daily life of the city of Rio de Janeiro. The hypothesis that guides the arguments here is that there is a consistent musical movement local of street (especially concentrated in the Centre of the city) - which involves not only networks of musicians, but also producers and fans - which has contributed significantly to the construction of territoriality and the imaginary and/or in the city, in short, is subsidizing expressive processes of redefinition of social experience in this metropolis.

Keywords: Communication, Urban Culture. Brass Bands. 
Organizamo-nos a partir da movimentação de rua, especialmente da movimentação do carnaval e das fanfarras (1).

Matéria jornalística como esta abaixo publicada no jornal $O$ Globo passou a ser cada vez mais comum nos últimos anos e vem chamando a atenção do público para relevância das fanfarras.

Artistas que tocam em fanfarras entendem que a música de rua une as
pessoas (...) querem ocupar com a sua arte os espaços urbanos que estão
vazios, sem vida (...) estão ajudando o poder público a dar uma lufada de
ânimo no Rio de Janeiro (...). A ideia de reunir música, performance e
atitude política representa muito bem a emergente arte de rua carioca(2).

Ao mesmo tempo, pode se constatar examinando não só o destaque dado ao circuito de festivais internacionais de fanfarras - em eventos como o HONK! (3) e o Cirque et Fanfares Festival Internationa (4)-, mas também frequentando os concertos realizados regularmente por bandas notórias como Funkymuppets (em Paris), Pink Puffers (em Roma), Perhaps Contration (em Londres) ou The Original Big 7 (em Nova Orleans), que cada vez mais este universo musical vem mobilizando um público expressivo nos espaços públicos de diferentes localidades do globo. Poder-se-ia mencionar ainda o sucesso e a repercussão alcançada pela banda dos Siderais no último festival na última turnê nos EUA e o êxito junto ao público alcançado pela Orquestra Voadora na última edição do Rock in Rio (mega festival internacional do chamado mainstream), tocando em um dos palcos alternativos. Todos estes acontecimentos colocam em evidência a necessidade de se refletir como e porque a fanfarra - enquanto uma forma de expressáo cultural de rua - vem ganhando tantos espaços institucionalizados e não institucionalizados na sociedade contemporânea. Como será analisado neste artigo, no caso do Rio de Janeiro, isso está ficando cada vez mais claro, especialmente a partir de 2010.

\section{A articulação entre as fanfarras e o carnaval de rua no Rio de Janeiro}

Provavelmente se o escritor Joáo do Rio estivesse vivo e em atividade: para explicar a cultura musical de rua presente na atualidade descreveria uma cidade do Rio de Janeiro "submersa" (5) (quase "invisível") e que emerge com toda intensidade no carnaval. Ainda que isso só seja percebido claramente no carnaval, esta urbe é ocupada (especialmente na área central) de forma capilar pelos atores que, assim, em diferentes localidades, tocam, cantam e dançam, ressignificando seu cotidiano e a relação com os espaços públicos da localidade.

A trajetória do Sogoro Cosongo foi muito importante no Rio de Janeiro. O trabalho deles foi um marco, apesar do grupo não reunir muitos músicos brasileiros e de não atuarem como fanfarra. (...) O Sogoro Cosongo mostrou ao Rio, em 2005, que o Carnaval não é só marchinha, que é possível tocar qualquer tipo de música no Carnaval. Isso foi importante para o movimento musical de rua decolar e conquistar mais público. (...) Pode-se dizer que o Sogoro Cosongo foi a faísca, e a Orquestra Voadora, foi a gasolina. Ambos incendiaram a cidade! (...) Acho que o movimento das fanfarras no Rio hoje está chegando a um estágio de maturidade, 
mas ainda vai continuar crescendo (6)

Alguns frequentadores, especialmente os mais assíduos, descrevem uma cultura musical de rua carioca muito presente no seu cotidiano e que vem alterando os hábitos de consumo musical:

Costumo acompanhar as fanfarras e bandas que tocam na rua. Frequento também o carnaval de rua do Rio (...). Acho o máximo o pessoal tocar na rua, a verdade é que muita gente curte consumir música na rua (...). Eu mesmo quase não pago mais ingresso para ver shows. Além disso, muita gente não pode pagar um ingresso de show e tem assim a chance de acompanhar, de participar desta maneira. É a oportunidade de um maior número de pessoas consumirem cultura. É também uma oportunidade de misturar vários tipos de pessoas, de vários gostos e de diversas classes sociais. Pode-se produzir nesses encontros musicais uma explosão de alegria e ideias, às vezes ocorre uma comoçáo, muita catarse e variados sentimentos afloram nesses momentos. (...) O bacana da rua é que não é um palco, mas sim um lugar público, um espaço livre, bem propício para interaçóes e encontros entre as pessoas, mesmo para aquelas que passam e param para olhar e que participam só um pouco (...). Acho que intervençóes musicais como essas vêm despertando a sensibilidade das pessoas para a vida coletiva, se dá um sacode nas pessoas que em geral estão absorvidas no seu mundinho pessoal, que ficam só cuidando da sua rotina. (...) Acompanho várias bandas e grupos de rua da cidade. Este movimento começou, por volta de 2002, especialmente com a retomada do carnaval de rua, na onda de surgimento de blocos bacanas e importantes como o Boi Tolo, Boitatá e Céu na Terra. (...) Venho acompanhando principalmente o trabalho da Orquestra Voadora, dos Siderais e da Sinfônica Ambulante que armam shows individuais e batalhas de fanfarras bem animadas. Sempre que posso acompanho tudo, pois acho lindo o que esses músicos estão fazendo. Acho que estão mudando um pouco a cara da cidade (7).

Se, por um lado, ao longo da pesquisa e da revisão da literatura especializada realizada (8) pode-se constatar que a festa do carnaval (9) até o final dos anos de 1990, em certo sentido encontrava-se de certo modo "esvaziada"; por outro, pode se atestar também que no início do século XXI o carnaval carioca, impulsionado pela iniciativa espontânea dos atores sociais, volta a ganhar força através dos blocos (e bandas) que tomam as ruas da cidade.

Atualmente, o Rio de Janeiro vive uma espécie de explosáo do seu Carnaval de rua, à semelhança das primeiras décadas do século passado, a cidade é invadida por agrupamentos de foliôes organizados das mais variadas formas. Chamados indiscriminadamente de bandas ou blocos, esses grupos podem desfilar cantando um único samba composto especialmente a cada ano, ao som de marchinhas carnavalescas tradicionais ou de ritmos variados como maracatu, ciranda ou rock. O acompanhamento musical pode ser uma bateria, ao estilo das escolas de samba, uma bandinha "furiosa" ou uma mistura de vários instrumentos (BEI, 2007, p. 7).

Para muitos dos seus frequentadores e especialistas, este boom do carnaval de rua carioca representa a retomada da tradição do carnaval do século 
XIX e XX, isto é, uma retomada da festa espontânea dos entrudos, ranchos, cordôes e das sociedades carnavalescas (BEI, 2007; MARQUES, 2006), Sem entrar no mérito do debate sobre a tradição do carnaval local, é possível constatar algumas diferenças neste novo contexto do carnaval e que dizem respeito à expansão da temporalidade desta celebração e ao número de atores sociais envolvidos, especialmente de classe média. Para que se tenha uma ideia da importância dos blocos de rua no Rio de Janeiro: a celebração destes cortejos (e a sociabilidade que proporcionam) passaram a ocupar os meses de verão (mais especificamente o período após o réveillon) - foram convertidas em importantes atividades de entretenimento de veraneio - e, como consequência, ampliou-se oficiosamente a festa de carnaval de uma semana para dois meses de verão (no caso os de janeiro e fevereiro).

Crescentemente mais sensíveis aos benefícios que são gerados pela atuação dos blocos, o poder público tem procurado apoiar, normatizar e explorar o carnaval de rua com o objetivo de atrair visitantes e recursos ao Rio de Janeiro. É comum encontrar matérias publicitárias nomeando o carnaval do Rio como o maior do mundo, em função especialmente da escala de ocupação dos espaços públicos pelos blocos (HERSCHAMANN, 2013).

O poder público e a galera que gosta de música na rua só consegue ver o produto final, que é esse mega carnaval de quase dois meses que a gente tem aí hoje, no Rio de Janeiro, que é um carnaval diferenciado, com blocos temáticos, blocos tradicionais, blocos de músicos conhecidos, e blocos das fanfarras. Enfim, há no carnaval do Rio uma variação de propostas muito interessantes. Infelizmente, para o poder público, tudo é bloco. Tudo que está na rua é bloco, não percebem certos detalhes. Temos um carnaval que dá muito dinheiro para a Ambev, para os empresários e para todo mundo, mas quase não chega recursos para os grupos de rua. Os músicos tocam no carnaval, o dia todo, pra ganhar de 100 reais a 200 reais, enquanto a prefeitura e os empresários estão enchendo os cofres. (...) A verdade é que organizar um bloco é se meter numa grande enrascada! Quando um bloco consegue receber algum apoio é uma merreca, que varia entre cinco e dez mil reais. E ai, depois do desfile, tem que pagar uma série de despesas, mas faltam recursos. Tem que pagar carros de som, um monte de músicos e o serviço de segurança. Mas paga mal, uma merreca para todo mundo. E algumas pessoas acham que estes blocos de rua deveriam pagar mais de um milhão de reais, em direitos autorais ao ECAD. Isso só pode ser piada (10)!

Parte-se do pressuposto de que o crescimento do carnaval de rua na cidade do Rio de Janeiro desde meados da primeira década do século XXI está em alguma medida relacionado (mas não de forma exclusiva) a um ativismo musical realizado nos espaços públicos desta localidade por algumas redes de "prosumidores" (11). Em outras palavras, a hipótese que norteia este artigo é a de que há um movimento de música de rua que envolve grupos de músicos amadores, semiamadores (e até profissionais) que atuam não só em rodas de samba, choro e jazz, mas também na forma de fanfarras na cidade do Rio de Janeiro que vem contribuindo para o crescimento do carnaval de rua.

Ao longo do ano, esses jovens vêm mobilizando um público jovem expressivo 
que vem se acostumando a apreciar a experiência estética das "paisagens sonoras" (SCHAFER, 1969), isto é, com o consumo de música ao vivo - apreciar música de forma coletiva (e na maior parte das vezes de maneira gratuita) - vivenciado em praças, parques, praias e ruas-galerias da cidade do Rio, especialmente na área central da mesma (HERSCHAMANN e FERNANDES, 2012). Estes coletivos musicais - agrupamentos de "prosumidores" (CANCLINI et al., 2012), os quais estão organizados em "redes sociais" (CASTELLS, 1999) que atuam também na web - vêm ocupando e reterritorializando a cidade já há alguns anos. Assim, buscou-se neste trabalho acompanhar na medida do possível o cotidiano dos atores, ou melhor, inspirando-se nas suas críticas metodológicas feitas por Latour (direcionadas às ciências sociais modernas), procurou-se aqui estudar o social amalgamado e que gravita em torno das fanfarras. Contudo, o social não é encarado como uma “(...) esfera exclusiva ou um objeto particular, mas sim como um movimento peculiar de reassociação e reagregação" (LATOUR, 2012, p. 24). É preciso advertir o leitor que há um compromisso que orienta este estudo em curso e que é o de construir uma "sociologia das ausências e das emergências" a partir de "experiências sociais, políticas e culturais do Sul” (SANTOS, 2010).

A partir de uma extensa pesquisa de campo que vem sendo realizada de forma sistemática desde 2012 (12) - que envolveu não só a coleta, seleção e análise de matérias veiculadas na mídia impressa tradicional e material postado nas redes sociais, mas também observaçôes de campo e entrevistas semiestruturadas realizadas com os atores sociais (produtores, músicos e fấs/consumidores) - postula-se que, como alguns destes coletivos atuam também como blocos de carnaval de rua (vários bastante populares), há uma dificuldade em perceber que este ativismo musical de rua está alicerçando e impulsionando o crescimento desta importantíssima festa da cidade. Isto é, há uma "cultura musical de rua no Rio de Janeiro" atualizada pelas rodas, jam sessions e fanfarras (HERSCHAMANN e FERNANDES, 2011).

Apesar da violência e das condiçóes adversas, o carioca gosta muito de estar na rua: de beber na rua, de namorar, de encontrar os amigos na esquina. Desde criança o pai leva o sujeito na roda de samba e os cariocas estão habituados com isso (...) se sentem em casa na rua. (...) Por isso pode-se dizer que a cultura de rua do Rio de Janeiro é diferenciada, talvez única no Brasil (13).

Em outras palavras, há um processo de internalização de práticas, rotinas e habitus (BOURDIEU, 1991) que, apesar de não ter sido de modo geral constatado (e devidamente avaliado) pelo poder público e pela maioria dos especialistas do meio acadêmico, vem gerando resultados bastante significativos (benefícios socioculturais, econômicos e políticos diretos e indiretos), dos quais o estrondoso sucesso do carnaval de rua carioca dos últimos anos é a mais forte evidência. $\mathrm{Ou}$ seja, esta evidência analisada aqui se constitui em uma espécie de parte visível deste gigantesco "iceberg", que indicaria a enorme capacidade movente da música no mundo contemporâneo (14).

Acho que um dos diferenciais do ambiente cultural do Rio é que muita coisa rola 
na rua mesmo. Tocar na rua nesta cidade é muito bacana (...) acho que o carioca procura muito isso, a galera quer cultura e programa na rua (15).

Como já foi assinalado em outros trabalhos realizados e publicados (HERSCHAMANN, 2013), apesar da cidade RJ ser um importante "celeiro de música" (16) do país (HERSCHAMANN, 2010) e do carnaval carioca ser uma festa emblemática (um dos símbolos nacionais), até o final dos anos de 1990 esta celebração parecia estar praticamente restrita ao desfile do sambódromo (além dos ensaios das escolas de samba e alguns bailes de carnaval de clubes e agremiações), ou seja, constituía-se naquele momento em um evento bem mais restrito e, em grande medida, direcionado ao consumo do público externo.

Acho que algumas fanfarras estão na base da organizaçáo de um tipo de bloco
que está emergindo com muita força, nos últimos anos, no carnaval do Rio. E este
tipo de bloco tem atraído uma galera mais jovem e, claro, estão colaborando para
o grande crescimento do carnaval de rua, que temos acompanhado e participado
com grande entusiasmo (17).

\section{Música de rua e Cidadania}

Assim, parte-se do pressuposto aqui de que há uma espécie de ativismo ainda meio invisível e pouco compreendido pelos produtores musicais, pelo poder público e pela crítica. Aliás, um dos produtores mais ativos da cidade, Thiago Vedová, afirma em uma entrevista realizada em 2011 “(...) que o carioca está mal acostumado a não pagar pelos shows, habituou-se ao excesso de música gratuita oferecida na rua" (HERSCHAMANN e FERNANDES, 2012b, p. 7).

Talvez para um olhar mais "atento" ao novo "negócio da música" (que vem emergindo no século XXI) considere este "ativismo musical de rua" - o qual esta expresso na vitalidade das rodas, jam sessions e fanfarras que estão sendo criadas nos últimos anos na cidade - como uma inovação relevante. Ainda que não resolva o desafio da sustentabilidade no setor da música, estas inciativas podem estar sinalizando um "caminho alternativo" para que alguns jovens possam encontrar mais satisfação e realização na produção e consumo musical atual. Nota-se, neste conjunto de rotinas e práticas que gravitam em torno do espaço público, que não só os atores podem alternar a oferta de conteúdos de forma gratuita e paga, mas também que eles têm encontrado maneiras de financiar a oferta de música grátis na rua de forma continua. Além disso, com frequência nas entrevistas realizadas com os atores emerge: por um lado, menos uma preocupação com a "carreira" e com certos produtos que dão status aos músicos (ou que pelo menos ofereciam no século XX certo glamour a trajetória dos mesmos) - tais como CDs e DVDs -; e, por outro, mais uma constante preocupação com a inclusão, integração e ampliação das suas redes de fầs.

Queremos tornar a experiência com a música a mais inclusiva possível. Os ensaios da Orquestra Voadora que começam a partir do segundo semestre, no gramado do MAM, são para organizar o bloco que sai no carnaval, já que somos um grupo 
de fanfarra e bloco de rua. A proposta do bloco é bem democrática, é só chegar e tocar. É aberto a quem chegar. Claro que se chegar um cara tocando flauta e violão, provavelmente não vai dar porque somos acústicos e ninguém vai ouvir! A gente não vai excluir, deixamos todos participarem. A proposta é bem inclusiva. No carnaval chegamos a ter 100 ritmistas participando do desfile. (...) No bloco, algumas coisas são simplificadas porque, justamente, a gente não faz nenhuma seleção. Nenhum exame para ver quem toca bem ou mal. Então, para o carnaval, simplificamos os arranjos e o ritmo vai um pouco mais lento. Então, há diferenças na dinâmica e no repertório do gramado do MAM e aquele que o grupo executa nos concertos, no palco. No último carnaval arrastamos mais de 80 mil pessoas e a tendência é que este número de participantes cresça nos próximos anos (18).

A prática da inclusão social das fanfarras, de buscarem atingir o maior número de pessoas no trabalho de ocupação das ruas, tem levado a vários grupos a apostarem mais nas releituras do que no trabalho mais autoral.

(...) às vezes a gente toca música que é totalmente desconhecida e as pessoas cantam as marcaçóes de som... tipo... saem cantando... pam pam pam pam pam. E vão cantando os sons das músicas e é engraçado isso. E isso é uma coisa que, dentro da Orquestra Voadora, o pessoal comentava: ah, não vamos só tocar as músicas famosas para o público gostar. Quando a gente toca música menos desconhecida também dá certo. A gente toca uma desconhecida do Fela Kuti, mas o pessoal vibra porque a música é boa. A verdade é que a música sendo boa o pessoal curte também. Acho que sempre vão ter as duas coisas. (...) De todas as fanfarras a que tem a proposta mais autoral é o grupo Os Siderais. Mas as fanfarras inovam bastante nas releituras, nas performances, nos arranjos e nas fantasias que a galera usa (19).

Esta preocupação com o público não deve ser interpretada necessariamente (e de forma simplista) como uma preocupação com o mercado consumidor musical. Há uma dimensão política na atitude dos atores. Além disso, as fanfarras congregam de forma mais ou menos harmoniosa músicos amadores e profissionais. Nos eventos de música a colaboração de ambos é valorizada.

$\mathrm{Na}$ música de rua e nas fanfarras tem muito ativismo, mas claro tem também um pouco de preocupaçáo com a sobrevivência. (...) Neste universo musical se misturam pessoas com expectativas e objetivos diferentes. Então, as rodas de rua e as fanfarras são um movimento que mistura esses dois músicos: aquele que é o músico que vive só de música, que é profissional, e aquele músico que algumas pessoas chamam de amador, que não vive só desta atividade. (...) Há aqueles que têm uma experiência maior com música, mas isso não quer dizer que esses necessariamente tocam melhor que os outros (...). Às vezes você pode ter um cara que é muito técnico, mas que vai para a rua e não tem a pressão, não tem a pegada e a disposição que se exige de um músico neste contexto (20).

Esta se considerando as experiências sensíveis musicais, como experiências de afecção, carnais e estésicas, isto é, vivências que criam a possibilidade de penetração do mundo, através do corpo, em sua totalidade. No que se refere à estética: é sempre importante salientar, como faz Ranciére (2009), que esta não 
está restrita ao campo da arte. Está sendo considerada aqui, portanto, "vetor de comunicabilidade" e de "comunhão dos sentidos". Tal como propóe Maffesoli em seu livro Contemplação do Mundo (1995), aproxima-se a noção de estética a de ética, compreendida como uma forma de coabitar o mundo sensível e inteligível. Este autor define a "ética da estética", portanto, como "emoçóes compartilhadas", como "sentimentos em comum". Assim, para ele a ética da estética adquiriria materialidade nos estilos de vida dos agrupamentos sociais (MAFFESOLI, 1995, p. 35).

Como foi assinalado anteriormente, a principal preocupação dos músicos que atuam nas fanfarras cariocas é com a inclusão social, com a construção da cidadania que se daria pelo ato de ocupar as ruas de forma nômade e lenta (com tempo para a sociabilidade).

O neofanfarrismo foi uma ideia que a gente começou a usar depois, já no final de 2008. Fui um dos abraçou logo este rótulo. Tem um babado político nesta ideia (...). A gente defendia a ideia de que é "neo" porque somos diferentes politicamente das fanfarras tradicionais. Não é só uma reformatação das fanfarras, mas um posicionamento mais crítico perante o mundo. Assim, qualquer artista ou pessoa que trabalha com o grande público, tem uma responsabilidade ao atuar no espaço público. Tem uma responsabilidade histórica, social e ecológica com o mundo que o cerca. Se o músico se omite, está compactuando com o que já está ai. Assim, a ideia de "neo" representa uma rejeição àquela proposta anterior, não contra as fanfarras tradicionais, mas aquela postura do fanfarrão alienado que não valoriza o ato político de ocupar o espaço público. Então, o "neofanfarrismo" tem este lado ativista. Não é só acreditar num formato musical, mas é assumir uma posição mais crítica. (...) Evidentemente, este conceito de neofanfarra não é consensual e muita gente está focada mais na diversão e na zoação (...) (21).

Para Jacques, na sua releitura de Santos (2001) e Maffesoli (1987), a trajetória dos "homens lentos" e as "narrativas erráticas" são importantes porque nos posiciona dentro de outra perspectiva potencialmente mais crítica, a partir de uma "(...) história do que está na margem, nas brechas e nos desvios" (JACQUES, 2012, p. 24). Segundo a autora é preciso refletir sobre o que pode representar as diferentes expressóes de nomadismo nas cidades atuais, como, por exemplo, o movimento das fanfarras cariocas analisado aqui.

A ideia essencialmente é esta! Somos ambulantes e prontos para a rua (...). Estamos nas ruas para o que der e vier. $\mathrm{O}$ ambulante pode estar nas praças, pode estar nas ruas (...) (22).

Além das releituras de grandes sucessos musicais, outro aspecto sublinhado pelos artistas com frequência nos seus depoimentos é que as performances realizadas pelos músicos devem priorizar o volume e o resultado sonoro na rua - num ambiente marcado pelos desafios de fazer ouvir nas cidades polifônicas, dispondo só de instrumentos acústicos -, muitas vezes em detrimento da qualidade e da técnica. 
Então, as fanfarras têm um aspecto que envolve o contato direto com o público que, desde o início, a gente percebeu (...). Mesmo quando pensamos em gravar disco a gente ficou em crise. Discutimos muito até que ponto no disco vai dar pra mostrar a energia que a gente tem (...). A gente tem esse lado muito de performance que tem muito a ver com teatro, né? Em geral você não vai ver um vídeo de uma peça de teatro. Você quer é estar lá, ter uma experiência presencial. Então, o planejamento desde o início foi voltado muito mais para o show ao vivo do que desenvolver uma música para gravar. Então nunca ficou muito focado em disco, até porque está surgindo esse contexto de $\mathrm{mp} 3$, de internet onde o que é cada vez mais importante são mesmo as apresentaçôes ao vivo (...) (23).

$\mathrm{Na}$ rua a gente tem que tocar muito forte, com o som estourado, mas tocamos metade da música, ao invés de tocar ela toda. Se estamos tocando muito forte optamos por tocar só algumas partes, para poder se tocar aquelas onde se precisa de mais volume. É uma tática! Existe a tática do revezamento entre os músicos também, para não desgastá-los tanto. (...) Mas tocar na rua é lindo! Vale o esforço! É impressionante o efeito sobre o público. São mil olhares te olhando e olhares bem diferentes. (...) Gosto muito de tocar na rua por causa disso. E também pela gratuidade, porque a questão social é quase sempre importante para o pessoal que toca nas fanfarras (24).

A performance, portanto, ocupa uma centralidade na experiência que envolve as fanfarras (há uma consciência de que, talvez, o ato de se ouvir um disco desses grupos musicais em casa não reproduzirá o mesmo resultado no consumidor). Neste sentido, Zumthor - analisando os efeitos da presença, do ambiente e do corpo em ação - salienta a importância das performances para que as experiências sonoras sejam satisfatórias aos envolvidos (ZUMTHOR, 2000 e 2005).

\section{Trajetória das (neo)fanfarras no Brasil e no Mundo}

Como sugere Juba Pires, trombonista da Orquestra Voadora e Siderais, para compreender de forma mais densa e clara a dimensão cidadã e política das fanfarras é preciso rever um pouco da sua história.

Essa história toda das fanfarras começou na primeira metade da década passada, nesse movimento que a gente chama de neofanfarrismo, porque é uma nova roupagem desse formato fanfarra. A fanfarra é o formato de música mais antigo de música para as massas, mais antigo que a energia elétrica e rádio. Defendo essa tese de que a fanfarra seria o primeiro meio de comunicaçáo de massa instantâneo. Porque, antes de existir energia elétrica, podia ter uma autoridade falando, para um monte de gente, que o pessoal não ia conseguir escutar a uma grande distância. Então, a única coisa que propagava mais longe e que é uma forma de comunicação de massa eram as fanfarras, as quais usam os instrumentos musicais mais barulhentos. Então, o formato da fanfarra já existe há séculos, mas nunca se deu muita bolsa para isso (...). Na França e na Europa o processo histórico foi diferente. Os franceses desde os anos 60 e 70 já tocam na estrutura dessas fanfarras que mesclam o folclore com outros ritmos como o rock, soul e o pop. Na Europa, de modo geral, as fanfarras tradicionais continuaram existindo e por isso lá não teve esse hiato que permitisse a gente falar em um neofanfarrismo. Lá as fanfarras 
seguiram evoluindo, inserindo e atualizando gêneros musicais novos (25).

Segundo Guibert (1998) a origem das fanfarras estão relacionadas as bandas militares que emergiram no início do século XIX na França e são compostas por músicos que tocam instrumentos de sopro e percussão (26). A etimologia do termo "fanfarra" veio provavelmente do "fanfa" em espanhol, que se relaciona à "ostentação" e também da palavra árabe "farfar", que remete à ideia de falante e inconstante (27). Além da França, a estrutura e dinâmica musical da fanfarra foi adotada, aos poucos, em outros países da Europa. Em outros lugares, como os EUA ganhou outra roupagem - ficaram conhecidos como brass bands - e se articulou mais diretamente as bandas marciais (28). De modo geral, as primeiras fanfarras se notabilizaram nas celebraçóes pomposas e oficiais, muitas delas festas da coletividade local ou nacional.

Poder-se-ia perguntar a esta altura como surgiram as fanfarras populares e irreverentes? Pierre e Bridenne argumentam que esta mudança pode ter se iniciado com uma fanfarra conhecida como Fanfare des Beaux-Arts, entre 1889 e 1892 (PIERRE e BRIDENNE, 2007). Segundo o autor, um grupo de estudantes da Faculdade de Artes decidiu levar este estilo de música tradicional e "burguês" para a rua, atribuindo uma linguagem mais lúdica ao gênero. Tradicionalmente ligadas às cornetas e trombetes, as fanfarras foram com o tempo reunindo mais instrumentos, como a tuba e o saxofone, e aqueles que estivessem disponíveis e de fácil mobilidade. Ao longo do século XX, as fanfarras populares - voltadas para uma atmosfera de diversão (para a construção de um "pequeno carnaval") - começaram a se proliferar no âmbito universitário europeu (29). Com o tempo, os estudantes, que passaram a animar as festas e confraternizaçóes com as fanfarras e essas foram se popularizando ao ponto de passarem a ocorrer concursos entre as universidades. Nas décadas subsequentes, o repertório foi também se diversificando. Evidentemente, setores conservadores das academias de música frequentemente criticavam este tipo de prática, condenando especialmente a falta de originalidade das composições Os atores que tocam nas fanfarras contraargumentam que o ambiente gerado por esta prática é mais democrático, proporcionando a inclusão variados atores. Com o tempo, as fanfarras foram se espalhando pelo mundo todo e hoje não há um continente em que não encontremos este tipo de grupo musical.

No Brasil, o estilo da fanfarra - com características tradicionais - está articulado ao das bandas militares. Sua prática está espalhada pelo país e pode ser encontrado em desfiles cívicos, apresentaçóes em estádios esportivos e celebraçóes especiais na maioria das cidades brasileiras. Há algumas fanfarras que mesclam a estrutura tradicional das fanfarras com o folclore local, tais como os grupos Boi de Orquestra (de São Luiz, no Maranhão) ou a Fanfarra de Anguera (de Feira de Santana, na Bahia). Inclusive, na pesquisa foi possível atestar que há uma associação nacional, a Confederação Nacional de Bandas e Fanfarras, que é responsável por organizar o Campeonato Nacional dedicado as bandas militares e fanfarras (o maior dentre os inúmeros campeonatos que ocorrem em todo o país).

Evidentemente, as fanfarras (ou neofanfarras) cariocas analisadas aqui 
têm uma formatação e uma atuação no espaço urbano distintas deste universo das bandas militares e fanfarras tradicionais. É um movimento que emergiu como muita força na segunda metade da primeira década do século XXI. Como recorda um dos atores:

O Songoro Cosongo e a Orquestra Voadora fundaram este momento das fanfarras cariocas. O Songoro Cosongo é o irmão mais velho da Orquestra Voadora. Foram os primeiros a se organizar também como bloco. Quer dizer, este grupo tinha banda, mas o bloco estava dentro desse contexto carioca no qual surgiu o Céu na Terra, lá em Santa Tereza, e o Boi Tolo, aqui no Centro. (...) Essa mesma galera, que tocava nos blocos, formou a Orquestra Voadora, e, aí, o pessoal que também tocava lá (que não estava na Orquestra Voadora), foi formar depois Os Siderais. Então, Os Siderais também é irmão mais novo da Orquestra Voadora (...) E, depois, foram surgindo outras fanfarras (30).

\section{Expansão das fanfarras na cidade do Rio de Janeiro}

Em outras palavras, a música de rua vem sendo defendida pelos atores como uma prática "libertária" (emancipatória) que pode tornar mais acessível a experiência musical aos músicos e consumidores (ao se posicionarem na rua, estes atores afirmam que diminuem a dependência em relação aos tradicionais "intermediários" - tais como gravadoras, empresários, produtores, empresas de comunicação, etc. - para a realização dos concertos).

É interessante notar que a cultura musical de rua vem se ampliando especialmente no Centro do Rio de Janeiro. Parte-se do pressuposto de que a geografia e a arquitetura são vetores condicionantes e que vem contribuindo para a formação dessas "territorialidades sônico-musicais" (HERSCHAMANN e FERNANDES, 2012b). Os atores que atuam nestas redes de músicos e fẫs afirmam em seus depoimentos que as ruas do Centro por sua beleza e posicionamento geográfico facilitam e atraem o trânsito e o encontro entre os interessados e, assim, acabam se constituindo em uma espécie de "grande vitrine".

Existem muitos grupos que vão para a rua porque sabem que, especialmente as ruas do Centro, são uma vitrine (...). Vão para a rua com a intenção de ampliar seu público. Buscam ganhar visibilidade e, no futuro, vender o seu trabalho (...). Alguns músicos profissionais pensam assim: sou um profissional, né (...) vou para a rua pra fazer um trabalho de qualidade, sou diferente e toco melhor que os músicos amadores. E o Rio de Janeiro, para muitos deles, está tomado pelos músicos amadores, que estâo ocupando um significativo espaço de mercado. $\mathrm{Ou}$ seja, eles desenham a seguinte estratégia: depois que eu for para a rua e que fizer sucesso, vou poder fazer também shows em ambientes fechados e pagos porque já conquistei o coração da galera. Contudo, nem sempre as coisas saem como eles imaginam. (...) Ao mesmo tempo, tem muita gente que toca na rua porque acredita e sente prazer e liberdade nisso: independente de ser músico amador ou profissional, conhecido ou desconhecido do grande público (31).

Consequentemente, é possível constatar que estas redes de prosumidores vêm adquirindo cada vez mais visibilidade nas praças, jardins e "ruas-galerias" desta região. Reiterando argumentos desenvolvidos em trabalhos anteriores 
(HERSCHAMANN e FERNANDES, 2012b): no seu conjunto, estes elementos articulados a música constroem uma "paisagem sonora" (SCHAFER, 1969) capaz de mobilizar segmentos sociais significativos e que vem proporcionando uma série de benefícios diretos e indiretos aos atores locais e, de certo modo, às áreas das urbes em que atuam (HERSCHAMANN, 2007; HERSCHAMANN e FERNANDES, 2012b).

Nunca conseguimos apoio do pessoal do MAM, dos ambulantes locais ou da prefeitura. Ocupamos aquele espaço, que antes da nossa chegada, era meio abandonado, meio sinistro. Era bonito, mas abandonado e cheio de moradores de rua. Então, fizemos tudo totalmente na base da autogestão, no peito e meio mambembe, pois nosso estilo é rueiro mesmo. Nunca teve um lugar que a gente não tivesse conseguido tocar, até porque a gente não precisa necessariamente amplificar os instrumentos. Agora a gente percebe que depois da nossa chegada o lugar ficou mais bem frequentado e isso beneficiou a todos (32).

Como já mencionamos anteriormente, parte-se do pressuposto aqui que há uma correspondência entre os atores que promovem, ao longo do ano, a música de rua nesta cidade e os que organizam e participam de forma engajada no carnaval de rua.

O Carnaval do Rio, é um grande momento, é uma vitrine dessas manifestações musicais de rua. E o Carnaval do Rio de Janeiro é diferente de todos os carnavais de rua do Brasil, no sentido de que ele vem sendo conduzido especialmente por jovens de classe média da cidade. (...) As pessoas que tocam nas fanfarras e blocos estáo ali um pouco por conta do prazer de tocar para a galera e um pouco pela perspectiva de alavancar a sua atividade de músico. (...) Além dos blocos mais tradicionais, o pessoal das fanfarras ajudou a reinventar o carnaval de rua que mescla ritmos como, por exemplo, o pessoal da Orquestra Voadora faz. Alguns grupos também inventaram blocos temáticos como a proposta do Super Mario Bloco voltado para as músicas de games ou o Cinebloco com músicas de trilhas de filmes conhecidos (33).

Há algumas evidências de que este ativismo musical que vem tomando as ruas do Rio na última década é um fenômeno de classe média e que está concentrado na Zona Sul. Analisando o perfil dos prosumidores constatamos que, em sua grande maioria, são jovens estão numa faixa etária entre 16 e 30 anos. A grande maioria vive com os pais estão na condição de "moratória social" (34) e, portanto, a pressão por garantir sua sustentabilidade é menor que a de outros jovens com menos recursos. Em outras palavras, possuem tempo e condição socioeconômica para se lançar nesta rede colaborativa, isto é, podem ainda se arriscar a não mercantilizar tanto seu trabalho e a relação com o público.

\section{Considerações finais}

Tendo em vista o estudo de caso analisado, poder-se-ia afirmar que esses jovens destas redes pesquisadas (e que participam da cultura musica de rua do Rio) são empreendedores - ainda que não tenham emprego 
formal e não estão institucionalizados -, isto é, são trendsetters (como sugere CANCLINI et al., 2012), pois podem apontar tendências, ou melhor, podem ditar novos modismos.

Está rolando, já há alguns anos, um movimento de fanfarras no Rio, de música de rua, um movimento de engajamento nos novos blocos de rua. E o Orquestra Voadora foi precursor nisso, deu sua contribuição. (...) Claro, que existiam na França fanfarras tocando rock, funk e outros ritmos, com propostas bem humoradas e despojadas e isso inspirou a gente. Intuímos que isso poderia dar certo no Rio. (...) Ao mesmo tempo, acho que gente deu a sorte de juntar pessoas que estavam no mesmo momento de vida, vivendo um momento musical especial da cidade. Nós somos músicos que tínhamos estado em blocos de Carnaval importantes da retomada do carnaval de rua carioca, como, por exemplo, o Céu na Terra, Boi Tatá e Boi Tolo. Ou seja, esses blocos também foram importante fonte de inspiraçáo para nosso trabalho. Além dos franceses, a gente se deu conta também de que as brass-bands nos Estados Unidos faziam trabalhos que também eram muito inovadores. (...) Tudo isso inspirou a gente e foi importante. Ao mesmo tempo, acho que conseguimos fazer algo inusitado, trouxemos uma novidade com o trabalho do Orquestra Voadora. Claro que existe estes movimentos de músicos de rua nos EUA e na França, mas acho que conseguimos, de forma espontânea, trazer algo novo para o cenário nacional. Tem muito grupos do Brasil e do exterior que são mais técnicos, que tocam muito bem. Mas a Orquestra Voadora é mais focada em brincar e interagir com a galera, talvez a gente seja mais forte nesse sentido. É muito bacana perceber que hoje tem muito adolescente e uma galera na faixa de 20 anos que quer e se encanta em tocar trombone e trompete. (...) É muito bacana também você se dar contar que há hoje no Rio um movimento de fanfarras, que alguns são também blocos e outras não, mas todas com propostas muito interessantes. (...) Assim de memória, posso dar alguns exemplos de grupos que compóe este movimento de fanfarras (...). Sem dúvida, destaco o trabalho da Sinfonica Ambulante, da Orquestra Voadora, do Cinebloco, dos Siderais, do Go East Orkestar e da Orquestra da Fanfarrada (35).

Diferentemente do que se frequentemente imagina: se aplicada políticas públicas inclusivas, de possíveis responsáveis por trazer "problemas sociais" estes jovens, portanto, poderiam ser convertidos em agentes de inovação, os quais podem contribuir em algum nível para a "revitalização" de megacidades (como a do Rio). A verdade é que estes atores - mesmo que isso não seja percebido desta maneira - podem estar gerando importantes renovaçóes e conduzindo processos tão desejados de recuperação e dinamização do espaço urbano.

Talvez possa se vislumbrar no horizonte um novo "negócio musical" (para além do mundo do indie e do mainstream), que já possui seus esquemas de financiamento organizados.

Usamos sites de financiamento coletivo (crowdfunding) e editais públicos, mas não passamos chapéu na rua, pois no Brasil isso não é bem visto. $\mathrm{Na}$ Europa, grandes músicos fazem isso, sem problemas, mas aqui o pessoal desvaloriza. (...) Buscamos recursos através de apoio oficial ou do nosso site. (...) Graças a um edital do Ministério da Cultura de intercâmbio cultural fizemos ano passado uma 
turnê pela Europa. Tivemos a oportunidade de ir para França, Portugal, Espanha, Bélgica e Inglaterra (36).

Em outras palavras, na atuação desses coletivos - já que esses trazem claramente reflexos positivos que vão muito além destas redes socioculturais e subsidiam significativamente o incremento da cadeia produtivo da gastronomia, do entretenimento, e especialmente a do turismo (como no caso do carnaval de rua do Rio) -, pois espaços da cidade são claramente favorecidos por este tipo de ocupação. Em resumo, as "territorialidades sônico-musicais" (HERSCHAMANN e FERNANDES, 2012a) que são elaboradas pelos atores geram inúmeros benefícios diretos e indiretos, revitalizando localidades importantes da cidade (como os corredores culturais e centros históricos) que são escolhidos por eles a partir de alguns critérios básicos:

\footnotetext{
Para escolher o local para tocar, temos alguns critérios que não são muito definidos, mas que são basicamente: avaliamos onde a gente pode conseguir tocar, sem que o grupo seja interrompido. Selecionamos um espaço onde a gente pode conseguir tocar e mobilizar uma galera que não necessariamente nos conhece (...). Em geral, o pessoal que toca na rua tem isso em mente quando procura um espaço para tocar (...). Já tocamos na Praça Tiradentes e na Praça XV, além de locais menos concorridos e visados pelos grupos de rua, que em geral estáo concentrados no Centro da cidade (37).
}

Em suma, talvez com uma participação mais efetiva do poder público ampliando o número de editais de financiamento - dos quais alguns artistas já participam - essas redes de prosumidores musicais poderiam vislumbrar: não só a possibilidade de uma maior sustentabilidade para este tipo de inciativa, mas também oportunidades para a ampliação da sua atuação. Portanto, algumas áreas da cidade assim poderiam usufruir dos reflexos positivos da "capacidade movente da música” (HERSCHAMANN e FERNANDES, 2012a), ou seja, poderiam de alguma maneira se beneficiar mais dos processos de construção e popularização de atrativas "paisagens sonoras" (SCHAFER, 1969) urbanas. 


\section{Referências Bibliográficas}

BAKTHIN, Mikhail. Cultura popular na Idade Média e no Renascimento. São Paulo: Hucitec, 2010.

BEI. Guia do Carnaval de Rua do Rio de Janeiro. Rio de Janeiro: BEI Comunicação, 2007.

BOURDIEU, Pierre. La distinción. Madrid: Taurus, 1991.

BURNS, Mick. Keeping the Beat On the Street. Baton Rouge: Louisiana State University Press, 2006.

CANCLINI, Néstor G. Jóvenes, Culturas Urbanas y Redes Digitales. Madri: Fundación Telefónica, 2012.

CASTELLS, Manuel. A sociedade em rede. Rio de Janeiro: Paz e Terra, 1999.

GUIBERT, Gérome. Les Nouveaux courants musicaux: simples produits dês industries culturelles. Nantes: Éditions Séteun, 1998.

HERSCHAMANN, Micael. Indústria da música em transição. São Paulo: Ed. Estação das Letras e das Cores, 2010. . Lapa, cidade da música. Rio de Janeiro: Mauad X, 2007.

; FERNANDES, Cintia S. Potencial movente do espetáculo, da música e da espacialidade no Rio de Janeiro. In: RIBEIRO, Ana P. G.; FREIRE FILHO, João; HERSCHAMANN, Micael. (orgs.) Entretenimento, Felicidade e Memória: forças moventes do contemporâneo. Rio de Janeiro: Anadarco, 2012a.

; - Nova Orleans não é aqui? In: E-Compós. Brasília: Compós, vol. 15, n. 2, 2012b.

HERSCHAMANN, Micael. Apontamentos sobre o crescimento do Carnaval de rua no Rio de Janeiro no início do século XXI. In: Revista Intercom (RBCC). Sáo Paulo: INTERCOM, v.36, n. 2, p. 267-289, jul./ dez. 2013.

HOBSBAWM, Eric e RANGER, Terence. A invenção das tradiçôes. Rio de Janeiro: Ed. Paz e Terra, 1984.

JACQUES, Paola Berenstein. Elogio aos errantes. Salvador: EDUFBA, 2012.

JENKINS, Henry. Piratas de Textos. Barcelona: Paidós, 2010.

JOÃO DO RIO. Religiōes no Rio. Rio de Janeiro: José Olympio Editora, 2006.

JOÃO DO RIO. A alma encantadora das ruas. Rio de Janeiro: Cia. de Bolso, 2008.

LATOUR, Bruno. Reagregando o social. Florianópolis: EDUSC, 2012.

MAFFESOLI, Michel. O tempo das tribos. Rio de Janeiro: 
Forense-Universitária, 1987. 1995.

. Contemplaçâo do Mundo. Porto Alegre: Artes e Ofícios Ed.,

MARGULIS, Mario. La Juventud es más que una palabra. Buenos Aires: Biblos, 1996.

MARQUES, Márcio. A revitalização do carnaval de rua do Rio de Janeiro. In: Revista Jovem Museologia. Rio de Janeiro: Museologia/ UNIRIO, n. 1, janeiro de 2006.

MATTA, Roberto da. Carnaval, Malandros e Heróis. Rio de Janeiro: Rocco, 1997.

PIERRE, Jean L.; BRIDENNE, Michel. Guide de las Fanfares. Paris: Irma, 2007.

PIMENTEL, João. Blocos. Rio de Janeiro: Relume Dumará, 2002.

PRESTES FILHO, Luis Carlos. Cadeia Produtiva da Economia do Carnaval. Rio de Janeiro: E-Papers, 2010.

RANCIÉRE, Jacques. A partilha do sensivel. São Paulo: Ed. 34, 2009.

SANTOS, Boaventura de Souza. Gramática do Tempo. São Paulo: Cortez, vol. 4, 2006.

SANTOS, Milton. Elogio da lentidão. In: Folha de São Paulo (Caderno Mais). São Paulo, 11 de março de 2001, p. 2.

SCHAFER, R. Murray. The new soundscape. Vancouver, Don Mills, 1969.

VIANNA, Hermano. O Mistério do Samba. Rio de Janeiro: Jorge Zahar Editor/Editora UFRJ, 1999.

ZUMTHOR, Paul. Performance, recepção e leitura. São Paulo: EDUC, 2000 .

. Escritura e Nomadismo. São Paulo, Ateliê Editorial, 2005.

\section{NOTAS}

(1) Entrevista realizada com Pedro Araújo, percussionista do grupo Orquestra Voadora, concedida a pesquisa no dia 08 de março de 2013.

(2) GONZALEZ, Amélia. "Músicos querem tocar para alegrar espaços urbanos vazios" in O Globo. Revista de Domingo. Rio de Janeiro, 07 de setembro de 2012, p. 7.

(3) Sobre o Festival of Activists Street Bands, cf. o link: http://honkfest.org, último acesso: 03/01/2014.

(4) Mais informações sobre Cirque et Fanfares Festival International, cf. o link: http:// www.cirqueetfanfaresadole.com, último acesso: 03/01/2014.

(5) É esta a sensação o leitor tem ao ler ao alguns livros de Joáo do Rio - como, por exemplo: Religióes no Rio (2006) e Alma encantadora das ruas (2008) - sobre esta 
cidade no início do século XX.

(6) Entrevista com Bruno Di Nicola, trompetista do Cinebloco, concedida a pesquisa no dia 25 de setembro de 2013.

(7) Depoimento de J.A.S., estudante, 23 anos, concedido a pesquisa no dia 06 de maio de 2013.

(8) Tomam-se aqui como importantes referências as pesquisas realizadas sobre o carnaval carioca, por especialistas como Vianna (1999), Prestes Filho (2010), Cavalcanti (2006) e Pimentel (2002).

(9) Sobre o ritual do carnaval e sua dimensão dionisíaca e irruptiva, ver: Bakthin, 2010; Matta, 1997.

(10) Entrevista realizada com Miguel Maron, percussionista do grupo Os Siderais, concedida a pesquisa no dia 05 de junho de 2013.

(11) Sobre o conceito de prosumidores e consumidores produtivos ver Canclini et al., 2012; Jenkins, 2010. Estes autores postulam que já há alguns anos vem se fragilizando as fronteiras entre o polo da produção e consumo (que sugerem uma dinâmica interativa e colaborativa, na qual é cada vez mais difícil separar o produtor do consumidor).

(12) Este artigo traz alguns dos resultados preliminares do projeto de pesquisa intitulado "Comunicação, Música e Espacialidade". Agradeço, portanto, ao CNPq pelo apoio a esta investigação, a Cíntia Sanmartin Fernandes pelas contribuições e intercâmbio realizados durante a confecção deste artigo e, finalmente, as minhas incansáveis auxiliares de pesquisa de iniciação científica - Indira Oliveira, Jaqueline Neves da Silva, Diana Ferraz e Juliana Araújo - pela colaboração no levantamento de inúmeras informaçóes que foram importantes para a construçáo de inúmeros argumentos aqui expressos.

(13) Entrevista realizada com Marco Serragrande, trompetista do Monte Alegre Hot Jazz Band, concedida a pesquisa no dia 15 de janeiro de 2012.

(14) Herschmann e Fernandes (2012a) sublinham a enorme capacidade mobilizadora da música na atualidade, especialmente quando as iniciativas que envolvem sonoridades estão articuladas a indústria e lógica do entretenimento.

(15) Entrevista realizada com Leonardo Campos, trombonista da Orquestra Voadora, concedida a pesquisa no dia 08 de março de 2013.

(16) Há várias décadas esta cidade vem atraindo músicos e profissionais do setor e assim vem se constituindo no principal polo de produçáo do país (HERSCHMANN, 2010).

(17) Entrevista realizada com Miguel Maron, percussionista do grupo Os Siderais, concedida a pesquisa no dia 05 de junho de 2013.

(18) Entrevista realizada com Leonardo Campos, trombonista da Orquestra Voadora, concedida a pesquisa no dia 08 de março de 2013.

(19) Entrevista com Juba Pires, trombonista dos grupos Orquestra Voadora e Siderais, concedida a pesquisa no dia 01 de outubro de 2013. 
(20) Entrevista realizada com Miguel Maron, percussionista dos Siderais, concedida a pesquisa no dia 05 de junho de 2013.

(21) Entrevista com Juba Pires, trombonista dos grupos Orquestra Voadora e Os Siderais, concedida a pesquisa no dia 01 de outubro de 2013.

(22) Entrevista com Edson Mattos, saxofonista da Sinfônica Ambulante, concedida a pesquisa no dia 03 de dezembro de 2013.

(23) Entrevista com Juba Pires, trombonista dos grupos Orquestra Voadora e Os Siderais, concedida ao autor no dia 01 de outubro de 2013.

(24) Entrevista com Bruno Di Nicola, trompetista do Cinebloco, concedida ao autor no dia 25 de setembro de 2013.

(25) Entrevista com Juba Pires, trombonista dos grupos Orquestra Voadora e Os Siderais, concedida a pesquisa no dia 01 de outubro de 2013.

(26) A história das fanfarras, assim como suas características, está diretamente atrelada ao processo de formação da sociedade francesa. Guibert salienta a importância social das fanfarras, argumentando que a implantação dessas orquestras e bandas, conhecidas como fanfarras, permitiram a Igreja e ao Estado educar musicalmente o povo e assim possibilitaram que participassem da fundação da ideia de nação (Guibert, 1998).

(27) Mais informações, ver CUNHA, Antônio Geraldo de. Dicionário Etimológico da Língua Portuguesa. Rio de Janeiro: Lexikon Editorial, 2010.

(28) Nos EUA predominaram as brass bands e datam de meados do século XIX, quando uma série de mudanças tecnológicas e sociais produziram um novo tipo de formação musical que se tornou popular com artistas e público. As brass bands começaram a fazer sucesso efetivamente em Nova Orleans (no estado da Louisiana), no final do século XIX. As novas bandas poderiam conter os mais diversos instrumentos, incluindo trompetes, trombones, clarinetes, saxofones e percussão. A música tocada por esse grupos era uma mistura de influências das bandas militares europeias com o folk africano (levado aos EUA pelos afrodescendentes). Porém, no início do século $\mathrm{XX}$, ainda que as brass bands possuíssem grande popularidade no resto do mundo, nos Estados Unidos elas foram gradualmente desaparecendo, sendo substituídas pelas orquestras que utilizavam mais de instrumentos de madeira. Foi apenas nas últimas décadas que as brass bands voltaram a fazer sucesso no Estados Unidos. Atualmente, há mais de cem brass bands ativas nos EUA. Nos anos 70, a tradição das brass bands em Nova Orleans experimentou uma transformação, quebrando com o estilo tradicional e adicionando elementos do funk, hip hop e bebop nos seus repertórios (Burns, 2006). (29) Segundo Pierre e Bridenne, ainda que essas novas fanfarras adotassem um perfil mais popular, sem que percebessem, faziam uma alusão distorcida ao movimento inicial das fanfarras militares. Vestiam-se com divertidas e exageradas fantasias - hot-dogs humanos, diabinhos e muitas perucas - e, assim, de certa forma, faziam lembrar os trajes formais e excessivos dos militares (Pierre e Bridenne, 2007).

(30) Entrevista com Juba Pires, trombonista dos grupos Orquestra Voadora e Os Siderais, concedida a pesquisa no dia 01 de outubro de 2013.

(31) Entrevista realizada com Miguel Maron, trombonista dos Siderais, concedida a 
pesquisa no dia 05 de junho de 2013.

(32) Entrevista realizada com Leonardo Campos, trombonista da Orquestra Voadora, concedida a pesquisa em 08 de março de 2013.

(33) Entrevista realizada com Miguel Maron, percussionista dos Siderais concedida a pesquisa no dia 05 de junho de 2013.

(34) Margulis (e outros autores) define a "moratória social" como um prazo concedido a certa classe de jovens, que lhes permite gozar de uma menor exigência enquanto completam sua instrução e alcançam sua maturidade social. Esta moratória permitiria prolongar a entrada na vida adulta e, consequentemente, a necessidade desses atores assumirem várias responsabilidades (Margulis, 1996).

(35) Entrevista realizada com Pedro Araújo, percussionista do grupo Orquestra Voadora, concedida a pesquisa no dia 08 de março de 2013.

(36) Entrevista realizada com Leonardo Campos, trombonista da Orquestra Voadora, concedida a pesquisa em 08 de março de 2013.

(37) Entrevista realizada com Miguel Maron, percussionista do grupo Os Siderais, concedida a pesquisa no dia 05 de junho de 2013. 